\title{
Roma en la poesía de Ida Vitale: lengua, literatura y civilización
}

\section{Rome in Ida Vitale's Poetry: Language, Literature and Civilization}

\author{
Josefa FERNÁNDEZ ZAMBUDio \\ https://orcid.org/0000-0002-2201-2921 \\ Departamento de Filología Clásica (área de Latín), Universidad de Murcia, España \\ pepifz@um.es
}

\begin{abstract}
RESUMEN: En este artículo analizamos ejemplos significativos del diálogo de la poesía de la uruguaya Ida Vitale con el mundo clásico, centrándonos en cuál es su recepción de Roma a través de referencias a la lengua latina, a la literatura, la religión, la sociedad, la historia y la arqueología. El uso de estos elementos se encuadra en su búsqueda de la expresión exacta. Justifican nuestra aportación la relativa carencia de estudios sobre Ida Vitale en general y, específicamente, en torno a la tradición del mundo clásico en su obra, así como la contextualización de nuestros hallazgos en su poética.
\end{abstract}

Palabras clave: tradición clásica, Ida Vitale, literatura hispanoamericana, civilización

AвSTRACT: In this paper we focus on significant examples of the dialogue between the uruguayan poet Ida Vitale and the Roman World. We explore her reception of Rome through Latin Language and Roman Literature, Religion, Society, History and Archaeology. These elements are linked to the search of an accurate expression. The lack of studies on Ida Vitale, especially on Classical tradition, and the contextualization in her Poetics justify our contribution itself.

Keywords: Classical Tradition, Ida Vitale, Latin American Literature, Civilization

ReCiBIDO: 25/11/2019 • ACEPTADO: 29/02/2020 • Versión FinAL: 13/07/2020 


\section{INTRODUCCIÓN}

Este artículo analiza cómo presenta Ida Vitale el mundo latino en su poesía, y cuáles son las particularidades de su relectura del mundo antiguo. Para ello, nos centraremos en ciertos aspectos de su uso del latín y de referencias literarias, históricas, así como en otros elementos relacionados con la civilización romana, con el fin de buscar si hay un hilo conductor común que explique su presencia a lo largo de su obra poética.

Ida Vitale es, además de escritora, traductora, crítica literaria, profesora y ha sido esposa de los también escritores Ángel Rama ${ }^{1}$ y Enrique Fierro, ${ }^{2}$ de tal manera que no es extraño que le preocupe la búsqueda de la exactitud en la expresión. Con este objetivo, explora una lengua culta en la que tiene cabida el latín. Y en su intento por comprender, a través de la poesía, el mundo que nos rodea y las preocupaciones humanas, aparecen en su obra elementos vinculados con la antigua Roma en diversos contextos, que abarcan setenta años de escritura. ${ }^{3}$

Los premios recibidos en los últimos años han contribuido a empezar a llenar una carencia de estudios en torno a su poesía. ${ }^{4}$ Sin embargo, dada la amplitud y profundidad de la misma, aún encontramos un vacío en diversos aspectos, entre los cuales podemos contar su tradición del mundo clásico. ${ }^{5}$ Sin ser éste un tema principal en su obra, es una constante a lo largo de ella, de manera que resulta pertinente preguntarse si hay una visión que justifique por qué Ida Vitale reitera su interés en Roma y cuáles son las particularidades que ha escogido reflejar.

\section{AcerCAmientos A LA LENGUA Latina}

Como escritora y traductora, Vitale es consciente de que la lengua cuenta con un pasado. El alcance y significado de cada palabra y su elección no pueden ser ajenos a la herencia cultural y literaria que conllevan. Así lo

\footnotetext{
${ }^{1}$ Una figura relevante para entender la literatura uruguaya, cf. Concha 2012.

${ }^{2} \mathrm{Su}$ obra ha sido injustamente poco estudiada, cf. Courtoisie 2016. Comparte temas y concepciones literarias con Ida Vitale, por lo que sería interesante una lectura conjunta.

${ }^{3}$ Sobre la autora, debe verse Cañete Ochoa-Fernández Lanza 2019. En este libro aparece una completa biobibliografía, cf. Rocca 2019, pp. 147-206. Su Poesía reunida, editada por Aurelio Major en 2017, incluye poemas desde su primer libro, Luz de esta memoria, publicado en 1949.

${ }^{4}$ Cf. Bruña 2015; Cañete Ochoa-Fernández Lanza 2019. Los premios son numerosos. Destacamos el Premio Reina Sofía de Poesía Iberoamericana, recibido en 2015, y el Premio Cervantes, en 2018.

${ }^{5}$ Cf. Fernández Zambudio 2019.
} 
expresó la autora cuando recibió el Premio Reina Sofía de Poesía Iberoamericana:
en aquellas familias de palabras
que llegan del latín, vienen del griego
y uno debe acoger aun cuando, ciego,
ve saltar los sentidos como cabras. ${ }^{6}$

Dejando aparte la humorística imagen de la imposibilidad de aprensión de los sentidos que saltan como cabras, y la paradoja de que uno los ve ciego, ciertamente se muestra Vitale consciente de la continuidad desde el griego y el latín hasta el español, pero también de la dificultad que esa larga historia acarrea para determinar significados concretos. Esta riqueza es la que convierte a la materia prima poética, la palabra, en objeto de reflexión, hasta construir un discurso metapoético. ${ }^{7}$

La misma idea sobre la utilidad de las lenguas clásicas para poder adentrarse en los sentidos de la palabra aparece en sus declaraciones relativas a cómo escogió estudiar latín: "Yo prefería las menos prestigiosas clases de latín, que elegí en vez de inglés. Ambas eran opcionales. Opté por miss Shalita, que me dejó una buena base para las lenguas latinas y me libró de miss Effie". 8

Por su historia personal, posteriormente Vitale tuvo que reencontrarse con el inglés, ya que vivió en Austin (Texas) de 1989 a 2018. ${ }^{9}$ Sin embargo, agradece ese punto de partida que supuso conocer los rudimentos del latín para la configuración de su lengua poética. Esta relación con el latín como base es reconocida explícitamente para las lenguas derivadas, "las lenguas latinas", y esta base que asigna a sus conocimientos de la lengua madre debe vincularse con su labor como traductora, en cuyo desempeño ha manejado el italiano, el francés y el portugués (además del inglés y el alemán). ${ }^{10}$

La expresión exacta que busca Ida Vitale, esa preocupación por los significados que cada palabra arrastra, ha llevado a la autora a escoger minuciosamente los elementos de su lengua poética y, en consecuencia, a buscar el rigor. Esto abarca la incorporación de términos no usuales, que acarician un registro elaborado, y dentro de él cobra sentido la inclusión de cultis-

\footnotetext{
${ }^{6} \mathrm{El}$ discurso se encontraba en la página http://premioreinasofia.usal.es/, dedicada a los premios, mas inexplicablemente desapareció tras una actualización.

${ }^{7}$ Un acercamiento desde los diversos prismas de la poética de Vitale debe empezar por las reflexiones de Bruña 2015, pp. 7-63.

${ }^{8}$ Cf. Montelongo 2016.

${ }^{9}$ Cf. Rocca 2019, pp. 147-205.

${ }^{10}$ Cf. la exhaustiva bibliografía de las obras traducidas por Ida Vitale en Bruña 2015, pp. 79-82, y Bruña 2019, pp. 215-216.
} 
$\operatorname{mos}^{11}$ y el empleo de la propia lengua latina. Nos enfocaremos en este último aspecto.

Encontramos el latín en el título de algunos poemas: "Nunc ipsum" y "Montevideo-nota bene". En "Nunc ipsum", la poeta plantea la necesidad de centrarse en el aquí y ahora para lograr la escritura, esto es, la vida, impedida a veces por las imágenes desordenadas de la memoria. Mediante un paseo por elementos arquitectónicos que señalarían ese espacio de nuestra memoria, Ida Vitale nos invita a detenernos en la dulzura del momento específico: "Nacimos, sí, para morir nacimos. / Pero antes, cuánto es vida suave".

A Montevideo, le dedica varios poemas, como "Trastienda", "Montevideo" y "Montevideo, 2". ${ }^{12}$ En "Montevideo-nota bene", retoma el interés por su ciudad de origen y sus problemas. En este caso, el latinismo nos incita a prestar atención y, manifiestamente, no ha sido abreviado en las siglas N.B. En el poema toma relevancia la atención y la necesidad de hacer todo explícito, pues esa preocupación por Montevideo parte de la historia uruguaya y de cómo escribir después de lo ocurrido, cómo volverse hacia la poesía cuando lo social es acuciante, pero también de cómo no seguir viviendo y escribiendo, sin obviar la realidad.

Tanto "Nunc ipsum" como "Montevideo-nota bene" tienen el latín sólo en los títulos, de modo que esta lengua resulta adecuada para la concisión requerida en las pocas palabras del título que han de presentarnos el poema.

Dentro del poema "Verano" se describe el calor hasta sus últimas consecuencias, que lo conectan con el fuego. Así incorpora las siglas I.N.R.I. y nos explica en el siguiente verso su lectura: "igne natura renovatur integra", literalmente "la naturaleza entera (o completamente) se renueva por el fuego" ${ }^{13}$ aludiendo a la resurrección o renovación espiritual. ${ }^{14}$

Se trata de una lectura masona de estas siglas, ${ }^{15}$ que la iglesia católica resuelve como "Iesus Nazarenus, Rex Iudaeorum", "Jesús Nazareno, rey de los Judíos", a partir de la inscripción que Poncio Pilato mandó colocar en la cruz de Jesucristo como motivo de la condena que había merecido tal castigo (Juan 19, 19-20; en el resto de evangelios la inscripción varía

\footnotetext{
${ }^{11}$ Especialmente numerosos en Léxico de afinidades, cf. Olvera Mijares 2009, quien repasa junto a Ida Vitale la mescolanza que se produce en el léxico empleado e incluso erratas como "pater familia", en vez de "pater familias", en la definición de "origen".

${ }^{12}$ Nació en 1923 en Montevideo, residió en México y Austin (Texas) y volvió a Montevideo a finales de 2018, cf. Rocca 2019, pp. 147-205.

13 Todas las traducciones a lo largo del artículo son propias.

${ }^{14}$ Entre los rosacruces existen diversas lecturas de INRI, además de la señalada por Vitale, cf. Montesexto 2012.

${ }^{15}$ Cf. Ferrer Benimeli 2015. Recordemos que el abuelo de Ida Vitale era masón y anticlerical.
} 
ligeramente). ${ }^{16}$ Muchos crucifijos y otras imágenes de la crucifixión incluyen estas letras.

INRI hace, pues, referencia a la regeneración para la evolución. En esta lectura se basa Vitale para presentarnos el calor mortal veraniego como regenerador, ya que la destrucción absoluta que implica permite, a través de eliminar los límites de las cosas, alcanzar la esencia de las mismas.

En "La voz cantante", encontramos la oración en latín "timeo Danaos", pero hablaremos extensamente de ella en el siguiente apartado, a propósito de la recepción de la literatura latina en la uruguaya.

La familiaridad de la poeta con el latín aparece en la obra como consecuencia de su convicción de la importancia de esta lengua para conocer la propia, y parte de un encuentro durante sus estudios, que valora positivamente, con sus primeros conocimientos del latín de la mano de miss Shalita. Una anécdota personal nos demuestra su relación con la lengua latina desde una edad temprana también a través de su vida familiar: un día encontró un gastado libro que resultó ser la Ilíada en griego y latín, que su abuelo había traído consigo desde Italia en su viaje a Uruguay. ${ }^{17}$

El latín es, por tanto, una herencia familiar, que se refuerza asimilada por interés propio, pues escoge su estudio cuando tiene la opción. Posteriormente, desde su labor poética, la autora aprecia sus cualidades, como base de las lenguas romances y, por tanto, de los significados con los que, como poeta, debe batallar. Su concisión le resulta adecuada para emplearla en títulos de poemas, y la relación con una cultura que ha utilizado el latín como lengua vehicular la lleva hasta los masones para definir el calor veraniego.

\section{LITERATURA LATINA: LA ENEIDA}

La exploración, la profundización en los límites de la expresión conecta con el surrealismo, sin perder el sentido, en La voz cantante, un texto singular donde encontraremos diversas interrelaciones con el mundo latino en medio de una peculiar indagación en sonidos y significados. Publicado por primera vez en la revista Vuelta, ${ }^{18}$ este texto dividido en 14 párrafos, en prosa poética, ${ }^{19}$ sirvió para abrir el libro Procura de lo imposible (1998).

Entre las diversas referencias de $L a$ voz cantante, aparecen algunas sobre el mundo clásico, entre ellas un "erudito Heródoto" con "sus investigadas,

\footnotetext{
${ }^{16}$ Aparece en Mateo 27, 37, Marcos 15, 26, y Lucas 23, 38.

${ }^{17}$ Espinosa 2019.

${ }^{18}$ Fundada por Octavio Paz, cf. Flores 2010.

${ }^{19}$ Es decir, sin métrica y rima, pero sí con el resto de elementos propios de la poesía, es más, con un elaborado lenguaje poético, por eso resulta pertinente incluirlo en este estudio, cf. Jiménez Arriba 2005, pp. 123-144.
} 
halicarnásicas historias" que "nos agasaja con Jerjes y más Jerjes y al fin Artajerjes, que ya no hay paciencia" (La voz cantante, 5) y las Parcas, ya que imagina que "Hartas las aciagas de cortar hilos resolvieron tejer" ( $\mathrm{La}$ voz cantante, 10). En este texto hay una completa y divertida reconfiguración de temas y personajes de la Eneida de Virgilio.

En primer lugar, encontramos el verso latino al que aludíamos en el apartado anterior:

3- Llegó - sinn fein - hebdomadario el rabdomante que dudaba entre el kirieleisón y el Kuomintang - timeo Danaos et dona ferentes - y sin saludar al huésped descubrió que ahora, miserandas, todas las serpientes dormían despavoridas bajo la hierba, aunque no escondieran mucho el color de su piel.

El verso completo es "Quidquid id est, timeo Danaos et dona ferentes", ${ }^{20}$ se trata de una advertencia de Laoconte sobre el caballo de Troya: "sea lo que sea, temo a los dánaos incluso cuando traen regalos". La advertencia es conocida, y común su expresión en latín simplemente con "timeo Danaos". Vitale demuestra aquí que conoce el texto virgiliano, para insertarlo en un contexto donde hallamos una mixtura de referencias pertenecientes a diversas culturas, que abarcan desde el irlandés sinn fein hasta la duda entre el canto propio de los entierros cristianos y el partido nacionalista chino ("Kuomintang") que tiene el semanal ("hebdomadario", con un término inusual y sonoro) rabdomante (la rabdomancia o radiestesia permite percibir dónde hay manantiales y vetas de metales). Las referencias sirven para jugar con la sonoridad y para crear un calidoscopio cultural, donde los elementos se encuentran y desencuentran con su significado originario.

La familiaridad con la Eneida se muestra en otros textos. En La voz cantante, 11, a propósito del tema de la muerte, hallamos: "Después, será el itinerario eterno. Entonces habrá llegado tu Turno. - No, es Dido quien así corre - se inmiscuyó, eneasilábico, Eneas, pasando por el foro, fuera de época pero siempre inmejorable".

Si bien en este texto la autora desarrolla diversos aspectos de la Eneida, ${ }^{21}$ no es su objetivo la recreación literal de sus versos, y juega libremente con sus personajes. Turno se convierte en el nombre común 'turno', es decir, aparece en mayúsculas como nombre propio; pero en el contexto de la oración hace referencia a un lugar común, "habrá llegado tu turno". Esta ambivalencia nos traslada a la obra de Virgilio, donde Turno es rey de los

\footnotetext{
${ }^{20}$ Verg., Aen., II, 49.

${ }^{21} \mathrm{Al}$ menos en este fragmento, pues este texto numerado como 11 inicia con un verso tomado de un poema de Ramón López Velarde titulado "Hormigas", que dice "el pozo del silencio y el enjambre del ruido".
} 
rútulos, aliado de Latino y pretendiente de Lavinia, la hija de éste. Eneas le dará muerte en combate singular. ${ }^{22}$

También aparece Eneas, ${ }^{23}$ con el sonoro epíteto de "eneasilábico", en un juego de palabras que aprovecha la coincidencia del nombre propio con el principio del término para indicar que tiene nueve sílabas. Dicho héroe se pasea anacrónicamente por el foro, pues sus disputas con Turno en el Lacio tuvieron lugar mucho antes de la construcción del foro. ${ }^{24}$

No se encuentra junto a Eneas y Turno la razón de su disputa, Lavinia, sino Dido, la reina de Cartago. Los amores de ésta y Eneas son el tema del libro IV de la Eneida, aquí Dido es la que corre, en vez de Turno, según nos cuenta Eneas. En Virgilio, es el héroe troyano el que huye de la infeliz reina, provocando su suicidio..$^{25}$

En el primer fragmento comentado, la referencia es literal, reproduce el famoso verso relativo a la necesaria y no seguida precaución que los troyanos debían tener hacia los griegos. En el segundo, a partir de un juego de palabras, se demuestra un conocimiento de estos personajes y, lo que es más importante, una familiaridad, pues la construcción de estos textos linda con lo inconsciente, de modo que podemos afirmar que en el imaginario personal, trasladado al imaginario literario de Vitale, aparecen los protagonistas de la Eneida virgiliana. Juan Gustavo Cobo Borda ha definido uno de los caminos que, a partir de la asunción del vacío crea la poeta uruguaya, como "el juego exacerbado con el lenguaje, a través de sus afinidades de sonido y sentido". ${ }^{26}$ De esta manera, no hay un alejamiento absoluto del sentido, ya que la relación entre los tres personajes está bien atestiguada, si bien no existe un interés por vincularse con los versos virgilianos y su contenido, sino que el objetivo es la experimentación fónica.

Debemos detenernos en un contexto muy diferente por una referencia a Palinuro, que aparece en un poema de Mella y criba, titulado "No es la sombra": "Algunas veces flotas, Palinuro / llevado hacia las sílabas gloriosas". Palinuro es el piloto de Eneas, quien durante la noche desaparece de la nave porque cae dormido al mar y, según le cuenta al héroe troyano cuando lo encuentra en los infiernos, fue asesinado tras lograr alcanzar la orilla. ${ }^{27}$

\footnotetext{
${ }^{22}$ Sobre la historia de Turno y su relación con Eneas, cf. Verg., Aen., VII-XII. En torno a la pervivencia de esta rivalidad, cf. Harrauer 2008, pp. 280-289.

${ }^{23}$ El héroe troyano es el protagonista de la Eneida, que cuenta su viaje desde Troya hasta llegar al Lacio y asentarse en él, como los dioses disponen. Para su figura como héroe, proporciona un buen resumen Rodríguez Herrera 1990. La tradición ha mostrado un especial interés por su relación con Dido, como mencionamos en la nota 25.

${ }^{24}$ Para un estudio profundo sobre el foro romano, cf. Coarelli 1992.

${ }^{25}$ Sobre Dido, cf. Ruiz de Elvira 1990 y Montemayor 2018. Acerca de la tradición de Dido y Eneas, cf. Harrauer 2008, pp. 232-235; Cristóbal 2002, y Hernández Lorenzo 2015.

${ }^{26}$ Cobo Borda 2010.

${ }^{27}$ Cf. Verg., Aen., V, 814-871, y VI, 337-383. Sobre este personaje, cf. Stok 2018.
} 
La versatilidad de los conocimientos y del uso de la Eneida por parte de la poeta son evidentes en los textos citados. El reflejo de la literatura latina que seleccionamos demuestra que, al igual que el latín, la literatura forma parte de su acervo cultural. Vitale no se dirige a textos específicos, sino a los arquetipos que ha formado la tradición, a través de ciertos personajes significativos, que sirven como punto de partida para una recreación propia en un nuevo contexto.

\section{HiSTORIA Y CIVILIZACIÓN ROMANA}

Ida Vitale trata de reflejar en su obra una amplia herencia linguística y cultural, y no olvida el mundo grecolatino: las palabras, que viene del latín, según la visión que nos recordaba en su discurso para recibir el Premio Reina Sofía; la lengua latina, utilizada en ciertas ocasiones; la literatura, en la Eneida, como vimos en los ejemplos proporcionados al respecto. Esta relación con el mundo antiguo se debe también a su herencia familiar, pues el abuelo de Ida Vitale, además de traer en su viaje la Ilíada bajo el brazo, decidió poner a sus hijos nombres no religiosos, de acuerdo con sus convicciones anticlericales y masónicas, para ello acudió a la historia romana, según comenta la autora en "Abuelo":

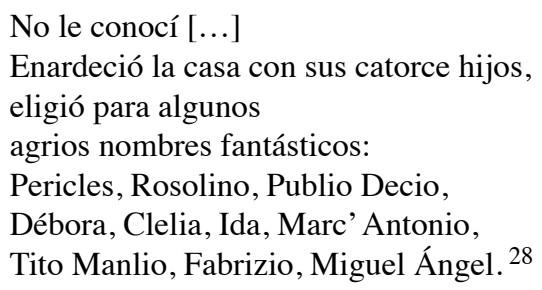

Además de Marco Antonio, entre estos nombres destacamos los menos conocidos de Clelia, Tito Manlio y Publio Decio, que se refieren a tres personajes pertenecientes a los héroes históricos romanos cuyas vicisitudes relata el historiador Tito Livio en Desde la fundación de la ciudad. Tratamos, por tanto, con una referencia que puede considerarse histórica y literaria, relacionada con las apariciones de personajes virgilianos señaladas en el apartado anterior.

\footnotetext{
28 También recuerda a su progenie en la entrada dedicada a "Abuelo", en Léxico de afinidades, 2012, donde cuenta que tenía "una cabeza romana" y que no quiso casarse hasta que no hubiera un registro civil para no pasar por "las que consideraba las horcas sagradas", comparando rendirse a una boda religiosa con la humillación sufrida por el ejército romano en las horcas caudinas.
} 
Recordemos que Clelia fue rehén de los etruscos, pero huyó cruzando el Tíber a nado. Porsena la reclamó, no le infligió daño y mostró admiración por su valentía. ${ }^{29}$ Tito Manlio y Publio Decio fueron cónsules en el año 340 a. C. y protagonizaron sucesos de la Segunda guerra contra los latinos, parte de la progresiva expansión de Roma. Publio Decio Mus se sacrificó para otorgar la victoria a los romanos. Tito Manlio Torcuato es famoso porque condenó a su propio hijo a muerte por desobediencia militar. ${ }^{30}$

La familia de Ida tiene, entre otras peculiaridades, nombres propios romanos, que pertenecen a personajes que sobresalieron por su fortaleza y su honor. De nuevo, desde las raíces de la poeta encontramos la relación con el mundo latino. ${ }^{31} \mathrm{~A}$ partir de esta base y de sus propios intereses, Ida Vitale no sólo ha asimilado la literatura y la lengua latina, sino también dicha civilización, pues a estas referencias históricas cabe añadir otras relativas a aspectos diversos de la sociedad romana, que nos hacen pensar que la conoce a detalle, aunque en sus obras no desarrolle una explicación detallada sobre cada tema particular. Veamos algunos ejemplos.

Un patricio surge inesperadamente en este texto de La voz cantante: "Pero - ¡agüaita la laucha! - le expletó un Patricio mientras le veía pasar". "Patricio" le permite la aliteración con "expletó". La hibridación entre referentes culturales que ya hemos podido observar en otros fragmentos de este texto permite que dicho patricio exhorte a observar un ratón (o una persona astuta, por las cualidades del ratón) con un término propio de Sudamérica. ${ }^{32}$

En unos versos dedicados a la hoja en blanco, aparece el prefecto del pretorio. Este cargo, que originalmente se refería al comandante de la guardia pretoriana, esto es, de la guardia personal del emperador, fue adquiriendo diversas funciones, entre ellas legales ${ }^{33}$ como bien señala Vitale en "Vórtice", donde el pánico ante la hoja en blanco se concreta en la tragedia de que la creación propia es impedida sobre todo por el veto que uno mismo se

29 Cf. Liv., II, 13.

${ }^{30}$ Liv., VIII, 3-12. Hay una curiosa anécdota respecto al nombre Publio Decio: un periodista entendió mal el nombre, por no conocer el referente, ni tener en cuenta la pronunciación de la poeta uruguaya, y a partir de él durante un tiempo se propagó en internet el nombre de Publio Tesio, cf. González 2018.

${ }^{31}$ Uno de sus hijos se llama Claudio (Rama Vitale), aunque resulta menos exótico que los nombres escogidos por el abuelo, Publio Decio, o Ida, que la poeta heredó de su tía. La tradición de nombres literarios y culturales no religiosos también la siguieron los padres de Ida, ya que el nombre completo de la escritora es Ida Ofelia, cf. Rocca 2019, p. 149 (nos proporciona estos datos en "Abuelo", en Léxico de Afinidades y en el poema "Abuelo", de los que hablaremos más adelante).

${ }^{32}$ Cf. RAE 2018.

${ }^{33}$ Sobre el poder que el prefecto del pretorio adquirió a lo largo del imperio, cf. Sancho Gómez 2011. 
impone: "Sobre todo cumple pretorianamente / tu encomienda: te veda / la justicia por propia pluma".

La especifidad de la referencia a una función del prefecto del pretorio demuestra una amplia cultura por parte de la autora, que la ha asimilado y volcado como parte de sus preocupaciones personales.

En relación con estas preocupaciones sobre el propio proceso de escritura, le importan a Vitale augures, augurios y sibilas, pertenecientes al terreno de la adivinación, ${ }^{34}$ que responden a su interés por los significados no evidentes y sus transmisores. Todos ellos son intérpretes de la magia de las palabras, que a través de ellos se transmiten. En este contexto debe comprenderse que las sílabas se transformen en "sibilas sediciosas" en el poema "Sílaba". Más allá del afán por jugar con los sonidos, hay, de nuevo, una interrogación por los misterios que encierran las palabras, e incluso sus componentes, las sílabas:

Pirarajú, piragua, Piranesi,
soberbios paladines pasajeros,
pájaros prismas apresados
en sílabas sibilas sediciosas
que suman sus enigmas.

Resulta destacable la relativa frecuencia con la que encontramos augures y augurios en la poesía de Ida Vitale. Dice José $\mathrm{M}^{\mathrm{a}}$ Espinasa que "nos parece a veces que habla con el lenguaje del sabio medieval, más mago que científico, y más brujo que mago, en el que toda palabra es metáfora". ${ }^{35}$ Aproximarse a leer a Ida Vitale resulta, en efecto, complicado no por la proliferación de referencias culturales, sino por la asimilación de las mismas en el contexto de una poética propia, donde tiene gran importancia una visión profunda, que no siempre se obtiene desde un acercamiento lógico. Por ejemplo, el gato es "augur del orden de las cosas" ("Gato") y resulta "como un augurio de la primavera" en sus "Elegías en otoño". Palabras de este campo semántico le permiten una vez más interactuar con el aspecto más lúdico del lenguaje, como en "observa sus agüeros, / inaugura" ("Sol tan tenue") o "inauguras tus peores augurios" ("Imagen del mundo flotante"). El misterio del mundo y de la escritura poética, que supone una forma específica de adentrarse en el mismo, encuentra en los augurios y los augures un referente útil para reflejar la imposibilidad de alcanzar la comprensión de una manera directa. El augurio revela, el augur permite esta revelación, y

\footnotetext{
${ }^{34}$ Acerca de la adivinación en Roma y la crítica a sus concepciones, cf. Espinosa Espinosa 2008.

${ }^{35}$ Espinasa 2019, p. 107.
} 
para Vitale la poesía ha de ser también revelación, de modo que se sitúa en una función semejante a la de estos antiguos sabios. ${ }^{36}$

La historia, la sociedad romana, incluso sus búsquedas espirituales a través de los augurios, se convierten gracias a la literatura en cotidianas, cercanas, asimiladas por Ida Vitale. También lo hace la arqueología en estos versos dedicados a "Roma":

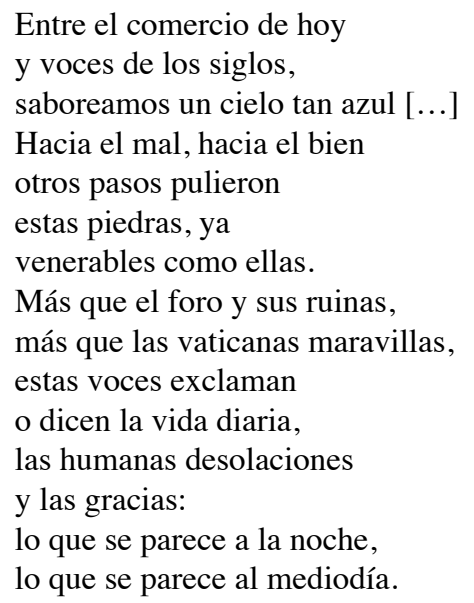

En estos versos es lo cotidiano tan venerable como la Ciudad Eterna. Frente a la frialdad de la piedra y la historia, la vida humana toma un papel preeminente. Roma y sus restos permiten dirigir la atención hacia la vida, y de la observación se parte para llegar al poema y para otorgarle el transfondo que la reflexión concede al verso. Recordemos que la reflexión es similar a la que le suscita su propia ciudad en "Montevideo-nota bene": el poema ha de volverse hacia la vida y sus problemas, ha de fijarse en lo que ocurre más allá del peso de la memoria, del pasado.

La función de las referencias que hemos recogido es diversa, pero en todos los casos se fundamenta en la necesidad de ahondar a través de la poesía en cuáles son los parámetros que permiten la creación y recreación, desde el lenguaje ("sílabas sibilas") al mundo como referente necesario (la Roma actual), y a los problemas de sus límites, que pueden ser abordados desde el mundo latino (la página en blanco, o los misterios que encierran las palabras).

\footnotetext{
36 Recordemos el título "Ida Vilate: la revelación exacta", de Corbellini 1997.
} 


\section{Conclusiones}

Debemos hablar no sólo de presencia del mundo latino en Ida Vitale, sino de vigencia, pues la poeta demuestra cómo la lengua y la cultura grecolatinas le permiten desarrollar una creación poética propia. Este mundo se encuentra en la raíz de su visión de la vida, por herencia vinculada a sus raíces familiares y por convicción personal de la necesidad de entender las palabras desde su historia. Ese fondo le permite reflexionar sobre su propia creación poética, los límites y problemas de la misma, y no duda en experimentar con los sonidos que le proporciona el mundo antiguo, sin perder de vista el acervo cultural que arrastra cada término.

Cabe preguntarse qué aporta el mundo clásico grecolatino a la obra de Ida Vitale. En los ejemplos de su poesía sobre los que reflexionamos, hemos podido comprobar que el mundo latino es una herencia recibida, no sólo a través de los estudios y de las lecturas escogidas, sino también gracias a ese abuelo, que no conoció, pero que marcó la vida de su familia. Esta herencia, que ella valora, es asimilada y volcada en su poesía sin perder de vista que la expresión poética elaborada permite profundizar en los sentidos transmitidos y en los sentidos nuevos de las palabras, en la ductibilidad del lenguaje como materia poética y en los referentes culturales como parte de la riqueza de cada término.

Reconocer los significados y las palabras como herederos del latín y, en ocasiones, emplear la lengua latina misma, junto con diversos elementos culturales que pertenecen a la riqueza de la civilización romana, que incluyen las costumbres, el orden social o la literatura, permiten un acercamiento a la expresión exacta, porque arrastran una historia que es continuamente renovada y replanteada en la creación propia. Como parte del rigor del lenguaje de Vitale y en su exploración de los límites expresivos, ${ }^{37}$ retoma sonidos y sentidos, léxico y significado proporcionados por la riqueza de Roma y del mundo romano.

El uso de la lengua latina, a veces en una posición tan relevante como en los títulos de los poemas, permite de forma concisa aludir a la necesidad de centrarse en el ahora ("Nunc ipsum" o a llamar nuestra atención ("Nota bene"). Nos hemos acercado a textos, como los de La voz cantante, donde el mundo antiguo proporciona una sonoridad específica. El diálogo con la Eneida, en particular, se produce desde esta perspectiva, y aparecen sus personajes en una situación completamente ilógica si la consideramos en relación con la obra de Virgilio. Lo mismo ocurre con algunos aspectos relativos a la civilización romana, como en "inauguras tus peores augurios"

\footnotetext{
${ }^{37}$ Corbellini 1997, p. 145, habla acertadamente de "Rigor culto y tenso con el lenguaje, que más bien parece una lucha por llevarlo a su límite expresivo".
} 
("Imagen del mundo flotante"). Sin embargo, sería superficial considerar estas referencias como meros añadidos, ante todo porque aparecen encuadradas en textos donde Vitale reflexiona sobre su propia labor poética, en torno a la página en blanco o al papel de las sílabas como elementos mínimos, sobre los límites que el creador se impone a través de la memoria.

Del análisis de los textos proporcionados podemos concluir que no existe un interés meramente ornamental para el uso de elementos pertenecientes a la lengua, literatura y civilización latinas. Forman parte de los conocimientos que Ida Vitale desea volcar en su obra, y los aborda desde puntos de vista diversos, que tienen un amplio recorrido. Los aspectos más lúdicos relacionados con los juegos sonoros son sólo aparentemente inocentes, pues permiten adentrarse en el problema de los significados, como demuestra la combinación de "sílabas sibilas", por ejemplo. Además, recoge ese mundo romano desde las perspectivas que más le interesan: la relación entre la poesía y la realidad que escoge reflejar, el prefecto del pretorio como referente del veto que la poeta se pone a sí misma, o Palinuro que flota hacia los sentidos.

Comentaba Ida Vitale en una entrevista: "Creo que hace bastante que me nutro de esa red de significaciones de las palabras que no están en la superficie del lenguaje, de ese fondo secular que se pierde o se adormila". ${ }^{38}$ Roma, como parte de esa historia de las palabras y parte de la historia de la civilización que las sustenta, es una de las bases de esa red que permite a Ida Vitale, mediante la profundización en las significaciones, configurar su lenguaje poético y su poética.

\section{BIBLIOGRAFÍA}

\section{Fuentes antiguas}

Los cuatro evangelios, trad. Alberto Colunga Cueto y Eloíno Nácar Fúster, Madrid, La Editorial Católica (Biblioteca de Autores Cristianos), 1969 (1957).

Tiтo Livio, Historia de Roma desde su fundación, trad. y notas José Antonio Villar Vidal, Madrid, Gredos (Biblioteca Clásica Gredos), 1982.

Titus Livius, $A b$ urbe condita, ed. and notes Robert Seymour Conway and Charles Flamstead Walters, Oxford, Oxford University Press, 1987.

Vergilius, Opera, ed. and notes Frederic Arthur Hirtzel, Oxford, Clarendon Press, 1966 (1914).

VirgiLIO, Eneida, intr., vers. rítmica y notas Rubén Bonifaz Nuño, México, Universidad Nacional Autónoma de México (Bibliotheca Scriptorum Graecorum et Romanorum Mexicana), 2006².

\footnotetext{
38 Mascaró 1993.
} 


\section{Fuentes modernas}

Bruña Bragado, Ma José, "Herida esencial y soberanía de la palabra", en Jesús Cañete Ochoa y Fernando Fernández Lanza (coords.), Palabras que me cantan, Madrid, Universidad de Alcalá, Servicio de Publicaciones, 2019, pp. 67-76.

Cañete Ochoa, Jesús y Fernando Fernández Lanza (coords.), Palabras que me cantan, Madrid, Universidad de Alcalá, Servicio de Publicaciones, 2019.

Coarelli, Filippo, Il foro romano, 1. Periodo arcaico. 2. Periodo republicano e augusteo, Roma, Quasar, $1992^{3}$.

Сово BoRDA, Juan Gustavo, "Ida Vitale", 2010, https://www.mcarts.com/cobo/ensayos/idaVitale-poesia.html (15/11/2019).

Concha, Pablo, "Presentación de Ángel Rama", Revista Pensamiento Político, 2, 2012, pp. 157-161, http://www.pensamientopolitico.udp.cl/edicion-dos/ (03/11/ 2019).

Corbellini, Helena, "Ida Vitale: la revelación exacta", en Heber Raviolo y Pablo Rocca (dirs.), Historia de la literatura uruguaya contemporánea, t. II: Una literatura en movimiento (Poesía, teatro y otros géneros), Montevideo, Ediciones de la Banda Oriental, 1997, pp. 145-163.

Courtorsie, Rafael, "Enrique Fierro (1941-2016): la construcción minuciosa de una micrología", Revista de la Academia Nacional de Letras, 12, 2016, pp. 119121, https://dialnet.unirioja.es/ejemplar/451812 (03/11/2019).

CRISTÓBAL, Vicente, "Dido y Eneas en la literatura española", Alazet: Revista de filología, 14, 2002, pp. 41-76.

EspinasA, José $\mathbf{M}^{\mathrm{a}}$, "Apuntes al margen para leer a Ida Vitale", en Jesús Cañete Ochoa y Fernando Fernández Lanza (coords.), Palabras que me cantan, Madrid, Universidad de Alcalá, Servicio de Publicaciones, 2019, pp. 105-113.

EsPinosa, Guillermo, "Ida Vitale: una entrevista a fondo con la Premio Cervantes", $M i$ lenio.com, 2019, https://www.milenio.com/cultura/laberinto/los-libros-nezahualcoyotl-y-la-vida-errante (03/11/2019).

EsPinosa EsPinosa, David, "La adivinación en Roma: orígenes, fundamentación y crítica especulativa de su práctica", Revista de ideas y formas políticas de la Antigüedad Clásica, 20, 2008, pp. 43-72, https://ebuah.uah.es/dspace/handle/10017/9402 (03/11/2019).

FernándeZ Zambudio, Josefa, "Mujeres que tejen y saben en la poesía de Ida Vitale", Impossibilia, 18, 2019, https://doi.org/10.32112/2174.2464.2019.318.

FerRer Benimeli, José Antonio, La masonería, Madrid, Alianza Editorial, $2015^{2}$.

FLoRES, Malva, "Un cuartel general hispanoamericano. Inicio y consolidación de la revista Vuelta (1976-1998)", en Regina Crespo (coord.), Revistas en América Latina: proyectos literarios, políticos y culturales, México, Universidad Nacional Autónoma de México-Ediciones Eón, 2010, pp. 505-536.

GonzÁlez, Enric, "Ida Vitale: El humor es esencial para sobrevivir", El País, 2018, https://elpais.com/cultura/2018/11/23/babelia/1542964304_979376.html $(15 / 11 / 2019)$.

HARRAUER, Christine, Diccionario de mitología griega y romana, Barcelona, Herder, 2008. 
Hernández LoRenzo, Laura, "Dido: el personaje virgiliano y su transmisión en la literatura española”, Philologia Hispalensis, 29/1-2, 2015, pp. 51-65, https:// revistascientificas.us.es/index.php/PH/article/view/2932 (03/11/2019).

JimÉnEZ ArRIBA, Carlos, "Estudios sobre el poema en prosa", Signa: revista de la Asociación Española de Semiótica, 14, 2005, pp. 123-144, http://www.cervantesvirtual.com/obra/estudios-sobre-el-poema-en-prosa-0/ (14/11/2019).

MAJor, Aurelio (ed.), Ida Vitale. Poesía reunida, Barcelona, Tusquets, 2017.

Mascaró, Roberto, "Con Ida Vitale: La poesía es irremplazable", El País Cultural, 209, 1993, http://cedros.edaddeplata.org/docactos/4395/Dossier_de_prensa/ Dossier_de_prensa04395002.pdf (14/11/2019).

Montelongo, José, "Entrevista a Ida Vitale", Letras libres, 2016, https://www.letras libres.com/espana-mexico/literatura/entrevista-ida-vitale (03/11/2019).

Montemayor Aceves, Martha Elena, "Figuras femeninas en la Eneida", Nova Tellus, 36/1, 2018, pp. 43-64.

MonteseXto, Phileas del, El peregrino de la rosacruz, Madrid, Opus Philosophicae Initiationis, 2012.

Olvera Mijares, Raúl, “Entrevista con Ida Vitale”, Armas y letras, 82-83, 2009, 78-80.

Real Academia Española, Diccionario de la lengua española, 23. a ed., 2018, https:// dle.rae.es $(03 / 11 / 2019)$.

Rocca, Pablo, "Una cronología biobibliográfica”, en Jesús Cañete Ochoa y Fernando Fernández Lanza (coords.), Palabras que me cantan, Madrid, Universidad de Alcalá, Servicio de Publicaciones, 2019, pp. 147-206.

RodríGuez Herrera, Gregorio, "Eneas: la evolución de un héroe", Boletín Millares Carlo, 11, 1990, pp. 145-152.

Ruiz De ElvirA, Antonio, "Dido y Eneas", Cuadernos de Filología Clásica, 24, 1990, pp. 77-98.

Sancho Gómez, Miguel Pablo, "El prefecto del pretorio: una figura dominante de la política romana en el siglo III (192-284)", Potestas, 4, 2011, pp. 69-86, http:// www.e-revistes.uji.es/index.php/potestas/article/view/402 (03/11/2019).

Sток, Fabio, "Un héroe virgiliano anómalo: Palinuro", en Dulce Estefanía Álvarez (coord.), Visiones y aspectos puntuales de la épica grecorromana, Madrid, Centro Superior de Investigaciones Científicas, 2018, pp. 145-160.

Vitale, Ida, Léxico de Afinidades, México, Fondo de Cultura Económica, 2012².

VItale, Ida, Discurso en la recepción del XXIV Premio Reina Sofía de Poesía Iberoamericana, Salamanca, Universidad de Salamanca, 2015, http://premioreinasofia.usal.es/ (20/11/2018).

Vitale, Ida, Todo de pronto es nada, ed., intr. y sel. María José Bruña Bragado, Salamanca, Ediciones Universidad de Salamanca, 2015.

$$
\text { *** }
$$

Josefa Fernández Zambudio es doctora en Filología Clásica y posee un Máster de especialización en Formación e Investigación Literaria y Teatral en el Contexto Europeo. Se desempeña como profesora del Departamento de Filología Clásica (área de Latín) de la Universidad de Murcia. Es miembro del CEPOAT (Centro de Estudios 
del Próximo Oriente y la Antigüedad tardía), donde ha sido docente y directora de cursos y máster de especialización. También ha participado en la elaboración de la web divulgativa "InterClassica: investigación y difusión del mundo griego y romano antiguo". Ha presentado comunicaciones y publicado libros y artículos sobre la tradición y recepción clásica, con particular atención en la literatura hispanoamericana, como El sueño de la razón produce mitos: Sor Juana Inés de la Cruz y la tradición clásica (2019), así como sobre la divulgación e innovación didáctica de las lenguas clásicas. 